\title{
Cladophialophora bantiana and Candida albicans mixed infection in cerebral abscess of an HIV-negative patient
}

\author{
Linh Van Pham, ${ }^{1}$ Anh Truong Quang, ${ }^{2}$ Phuong Anh Ton Nu, ${ }^{2}$ \\ Thai Tran Duc, ${ }^{3}$ Hoa Nguyen Thi. ${ }^{2}$ \\ ${ }^{1}$ Department of Surgery, ${ }^{2}$ Department of Parasitology, ${ }^{3}$ Gamma Knife Center \& Neurosurgery Division \\ Hue College of Medicine and Pharmacy and University Hospital, Hue, Vietnam
}

\begin{abstract}
Cladophialophora bantiana is a black fungus recorded rarely as a cause of brain abscess. We describe the first case seen in Vietnam. A 35-year-old, previously healthy male, HIV negative, came to the hospital with a clinical diagnosis of brain tumor. He underwent surgery to remove the well-delineated circumscribed lesion. Pathology, directed physical examination and mycological examination revealed an abscess due to Cladophialophora bantiana, and Candida albicans. After two weeks of treatment with Fluconazole $400 \mathrm{mg}$ per day intravenously, the clinical response remained unsatisfactory. Therapy was then withheld per the family's request.
\end{abstract}

Key Words: Cladophialophora bantiana, Candida albicans, fungus, cerebral abscess.

J Infect Developing Countries 2008; 2(3):245-248.

Received 09 January 2008 - Accepted 26 March 2008

Copyright (C) 2008 Pham et al. This is an open access article distributed under the Creative Commons Attribution License, which permits unrestricted use, distribution, and reproduction in any medium, provided the original work is properly cited.

\section{Introduction}

Cladophialophora bantiana is a chromogenic filamentous fungus. This dematiaceous fungus is highly neurotropic and has been reported to cause uncommon central nervous system infections [12]. The route for entry of this fungus is unknown but infections have been reported in immunosuppressed and organ transplant individuals $[2,7,9]$. Only a few cases have been reported in the literature worldwide and treatment has often been unsuccessful $[4,6,10,11]$. Mark K. Lyons (USA) reported successful treatment with Voriconazole [9].

Cladophialophora bantiana saprophytes are found worldwide in soil, plant, and wood matter. This fungus is known to cause contamination in laboratories [2]. Cladophialophora bantiana is observed as a golden brown filament; the colour is due to melanin in the cell wall [12].

\section{Case Report}

The male patient, L.V.T., came from Thanh Hoa province, Vietnam. He was 36 years old, and employed as a fruit worker in a vegetable distributing factory in a Ho Chi Minh City (HCMC) market. The patient did not have a history of immunosuppression or transplantion but had a smoking habit. In 2002, he had a motorbike accident which resulted in head trauma with minor cerebral thrombosis. The patient was treated with medicaments and returned to normal health. Three months previous to our current examination, he presented at a HCMC district hospital with right extremity weakness, mild function control, and mild convulsion. Right cranial magnetic resonance imaging (MRI) was conducted and resulted in the diagnosis of a right parietal occipital region tumor due to cancer metastasis. The patient was referred to Gamma Knife Center of the Hue College of Medicine and Pharmacy Hospital for treatment.

Upon examination, the patient was lucid with a mild headache, and mild left hemiplegia. The patient tested positive for HbsAg and negative for HIV. Magnetic resonance imaging (MRI) of the brain revealed a tumor-like image in the right parieto- occipital region (Figure 1).

The patient was diagnosed with a primary brain tumor of the right parieto-occipital region. The treatment included surgery to remove the welldelineated, circumscribed lesion. Histopathology, 
direct examination, and culture of the lesion were performed. Pathology revealed central necrosis and granulomatous tissue in the periphery and the presence of fungus hyphe. In the mycological laboratory, direct examination with $\mathrm{KOH} 30 \%$ revealed pigmented hyphae and yeast-like cells (Figure 2).

Figure 1. Brain abscess on MRI image.

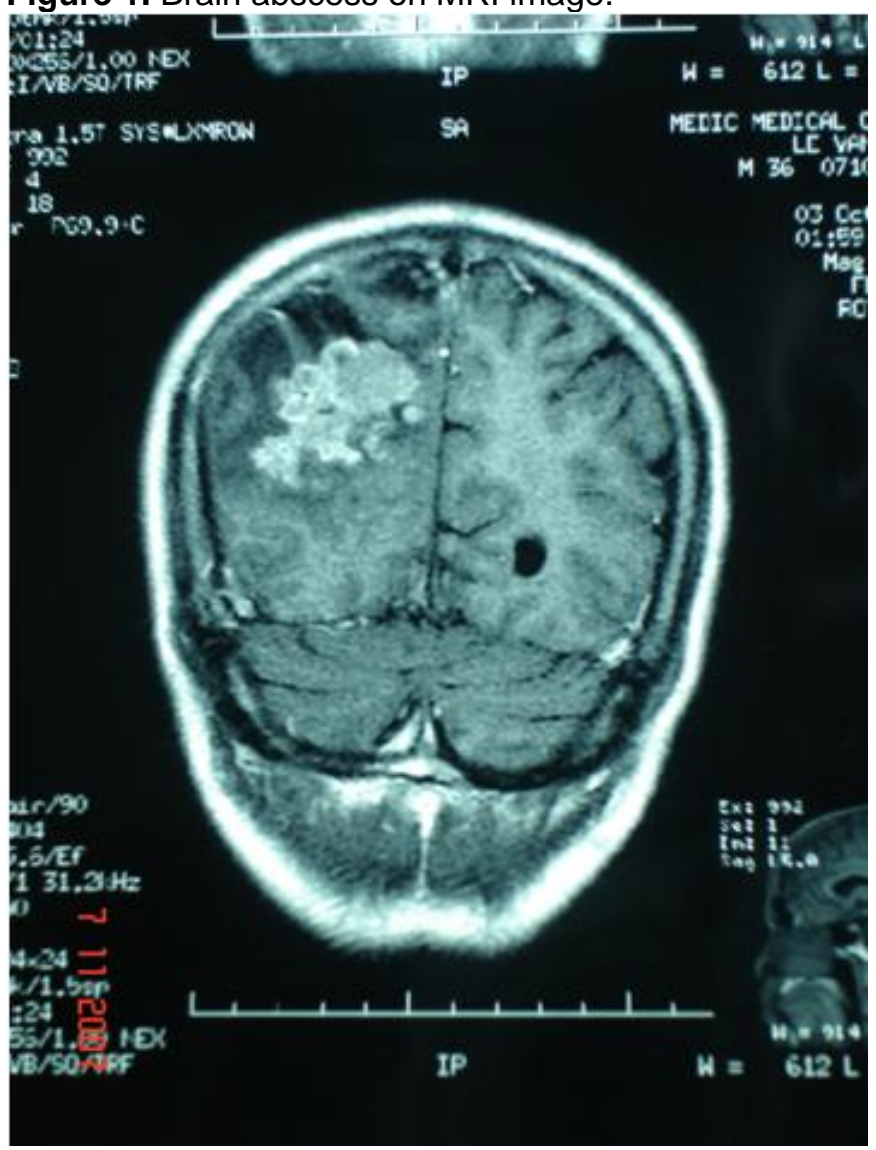

Figure 2. Direct examination with $\mathrm{KOH} 30 \%$.

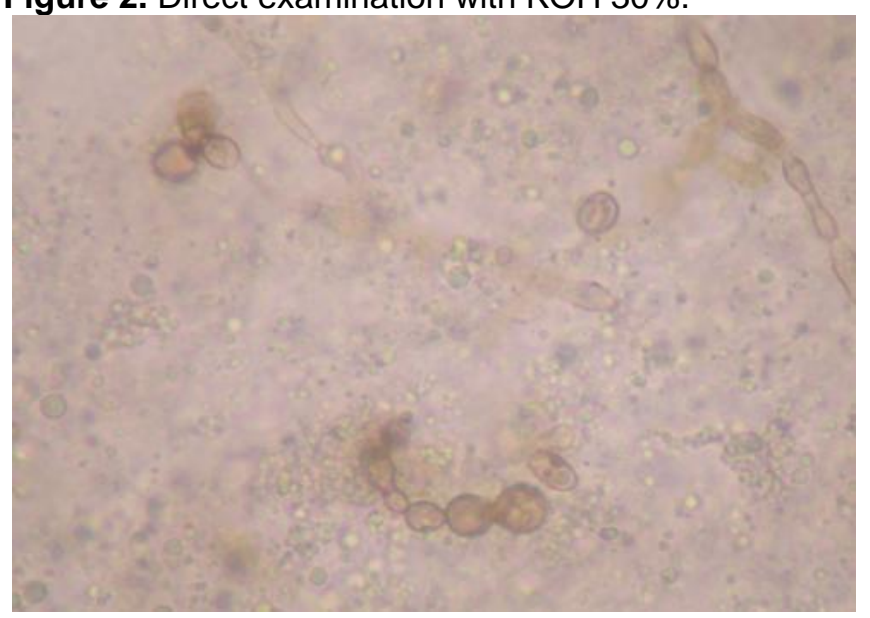

The lesion was routinely cultured on Sabouraud agar with chloramphenicol at room temperature and $37^{\circ} \mathrm{C}$. After 48 hours, yeast colonies grew better at $37^{\circ} \mathrm{C}$ temperature than at room temperature with milky white colonies. In addition, small black pigment septate hyphal colonies were observed. We prepared a germ tube test with egg yolk, urease test and culture on cornmeal agar to identify the yeast as Candida albicans (Figures 3, 4) [1,3,5,7,8,13,15].

Figure 3. Germ tube test with egg yolk to identify $C$. albicans.

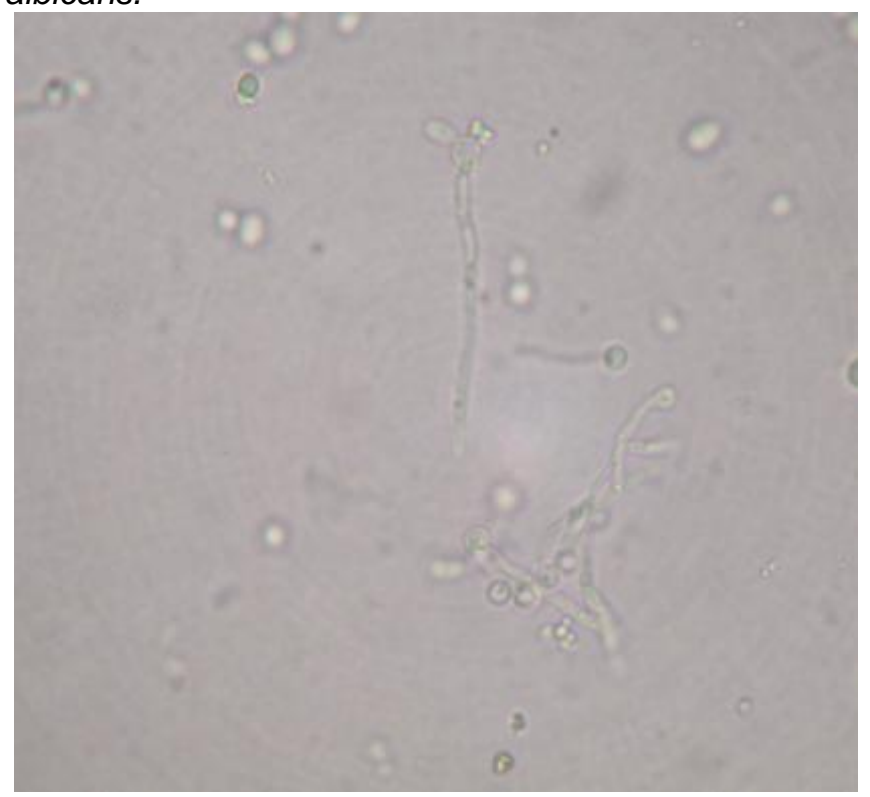

Figure 4. Chlamydospore of $C$. albicans.

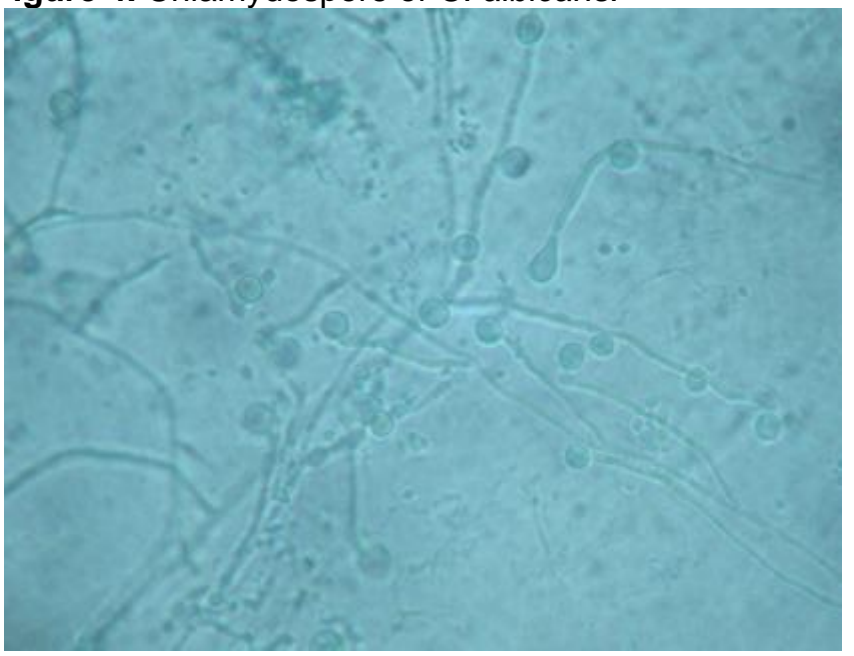

After one week, black pigmented hyphal colonies also grew better at $37^{\circ} \mathrm{C}$ than at room temperature. Observation of the mature mycelium 
and microscopy of culture confirmed Cladophialophora bantiana (Figures 5, 6).

Figure 5. Cladophialophora bantiana and Candida albicans cultured on Sabouraud chloramphenicol medium.

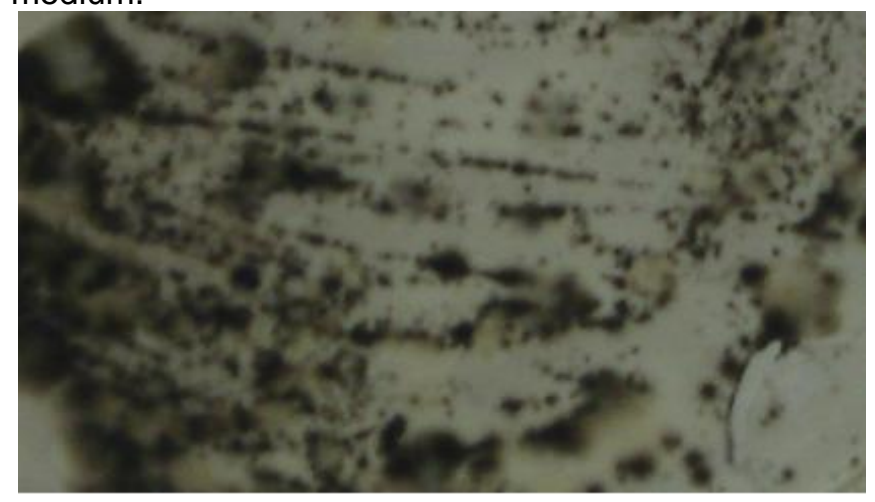

Figure 6. Cladophialophora bantiana in microscopic preparation stained with cotton blue.

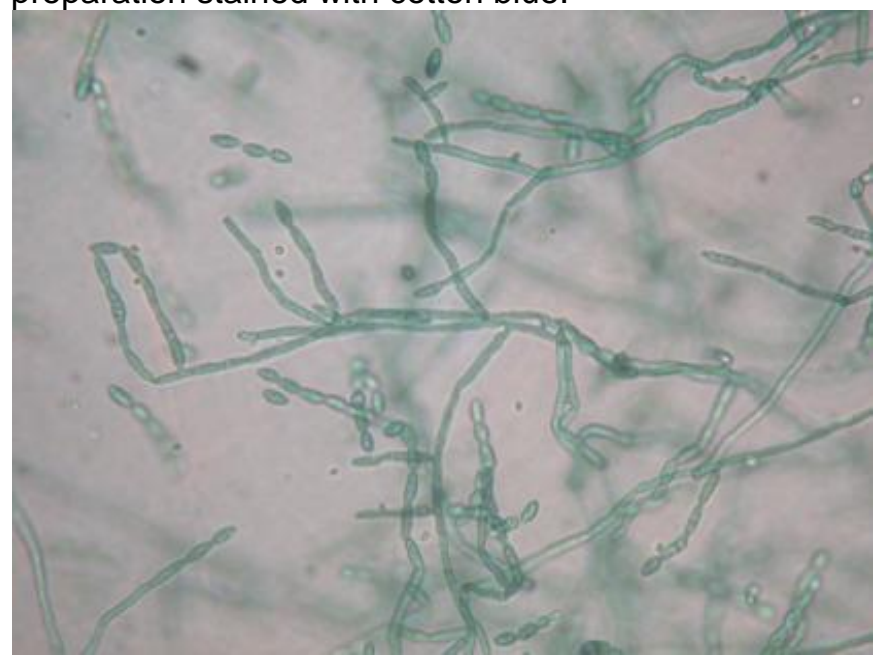

The final diagnosis was brain abscess caused by Candida albicans and Cladophialophora bantiana. The patient was treated with $400 \mathrm{mg}$ intravenous fluconazole per day. After two weeks of treatment, the clinical response to antifungal therapy remained unsatisfactory, and MRI image showed increased mass size. Therapy was then suspended per the family's request.

\section{Discussion}

Though the route of entry for Cladophialophora bantiana is not clear, the most widely accepted portal of entry is inhalation of spores followed by brain involvement via the hematogenous pathway $[7,11]$. Our patient had a brain trauma and worked in an environment that could be contaminated with Cladophialophora bantiana spores. Though the patient had no history of immunosuppression or transplantation, he did present a brain abscess infected with Candida albicans and Cladophialophora bantiana. These fungi could be found in external ear canals. We highlight these factors in order to supply more data for hypothesising the possible infectious route.

Cladophialophora bantiana is an uncommon cause of central nervous system infections. The symptoms of infection are headache and localized nervous signs. The disease is more frequent in males than females with a ratio of $3: 1$. The age of patients ranges from 6 to 77 years old. Brain abscesses can be single or multiple lesions which are easy to see on MRI images. Histopathology often shows central necrosis and granulomatous tissue in the periphery $[7,12]$. Direct examination of the pus with $\mathrm{KOH} 30 \%$ revealed the golden brown septate hyphae fungus with swollen cells at irregular intervals and branching of conidial chains. Giemsa staining showed similar morphology. Culturing the sample on Sabouraud agar with chloramphenicol at both room temperature and at $370 \mathrm{C}$ allowed the identification of black fungal colonies suggestive of Cladophialophora bantiana (Figure 6).

The optimal treatment of fungal Cladophialophora bantiana remains unclear. Surgical excision followed by appropriate antifungal drugs has not yielded encouraging results as 15 of 20 patients died despite aggressive surgical treatment and intensive chemotherapy. All patients showed recurrence and died within 3 to 11 months following surgery [11].

Lyon [9] reported the following minimum inhibitory concentrations (MICs) of Cladophialophora bantiana: Amphotericin B 0.5 $\mu \mathrm{g} / \mathrm{ml}$, Fluconazole $16 \mu \mathrm{g} / \mathrm{ml}$, Itraconazole $0.015 \mu \mathrm{g} / \mathrm{ml}$, and Voriconazole $0.03 \mu \mathrm{g} / \mathrm{ml}$. He also reported the first successful case of treatment of Cladophialophora bantiana cerebral abscesses with the relatively new antifungal agent voriconazole. However, Tüker [14] refers to a successful treatment case with Fluconazole 400 $\mathrm{mg} /$ day over 3 months. In another case reported by Rocke (13), Cladophialophora bantiana was sensitive in vitro to Amphotericin B, Itraconazole and Flucytocin, but the patient in this case was treated with Amphotericin B and Flucytocin unsuccessfully. 
Our patient received surgery and was treated with Fluconazole $400 \mathrm{mg}$ per day for 3 months. After 2 weeks, the lesion on the MRI image had spread and clinical staging was unsatisfactory. At the same time the family asked discontinuation of treatment and the patient was sent home. This confirms the difficulty of treatment of this type of infection when expensive antimycotic drugs are not easily available.

\section{References}

1. Badillet G, Bievre CD, Gueho E (1986) Champignons contaminant des cultures. Champignons opportunistes. Atlas clinique et biologie. Tome 1. Varia, Paris, pp.80-85.

2. Bioforma (2002), Les moisissures d'intérêt médical, Cahier de Formation, N.25. Bioforma, pp.114-115.

3. Drouhet E (1987) Coures de Mycologie médicale. Biologie des Candida et autres levures d'interet medical. Institut Pasteur, Paris, pp.1-8.

4. Freitas A et al. (1997) Cladophialophora bantiana (Previously Cladosporium trichoides): First Report of a Case in Brazil. Braz J Infect Dis 1(6):313-316.

5. Gentilini M (1993) Médecine tropicale, Flammarion Médicine - Science, pp.272-275.

6. Goel A, Satoskar A, Desai AP, Pandya SK (1992) Brain abscess caused by Cladosporium trichoides. $\mathrm{Br} J$ Neurosurg 6:591-3.

7. Hoog de GS (1995) Atlas of clinical fungi. Central bureau voor Schimmel cultures/ Universitat Rovirai Virgilli, pp. $89,144,222-223$.
8. Koenig H (1995) Guide de Mycologie médicale, Ellipses, pp.13-82.

9. Lyon MK, Blair JE, Leslie KO (2005) Successful treatment with voriconazole of fungal cerebral abscess due to Cladophialophora bantiana. Clin Neuro Neurosurg 107: 532-4.

10. Nadkani TD, Goel A, Shenoy A, Karapurkar AP (1993) Cladosporium bantianum (Trichoides) infection of the brain. J Postgad Med 39: 43-44.

11. Staib $P$ and Morschhauser J (1999) Chlamydospore formation on Staib agar as a species-specific characteristic of Candida dubliniensis. Mycose 42:521524.

12. Raut A, Muzumda D, Narlawar R, Nagar A, Ahmed N, Hira P (2003) Cerebral abscess caused by Cladosporium bantiana infection. Neurol Med Chir (Tokyo) 43: 413-415.

13. Roche M, Redmond RM, O'Neill S, Smyth E, A case of multiple cerebral abscesses due to infection with Cladophialophora bantiana. J Infect.2005; 51: 285-8.

14. Türker A, Altinors N, Aciduman A, Demiralp O, Uluoglu U (1995) MRI findings and encouraging fluconazole treatment results of intracranial Cladosporium trichoides infection. Infection. 234:60-2.

15. Walker TS (1998) Microbiology. W. B. Saunders Company, pp.290-317.

Corresponding Author: Dr. Phuong Anh TON NU, Department of Parasitology, Hue College of Medicine and Pharmacy and University Hosp., 6 Ngo Quyen Str., Hue, Vietnam, Email: phuonganh_tonnu@yahoo.com

Conflict of interest: No conflict of interest is declared. 